Published in: International Journal of Technology, Policy and Management, vol. 2 (2002), No 1, pp. 20-39

\title{
Innovating road traffic management by ITS: A future perspective
}

\author{
by \\ Rob van der Heijden \& Vincent Marchau
}

\begin{abstract}
The application of Intelligent Transportation Systems (ITS) is expected to improve the performance of road transportation significantly. Public policy makers, among others, are therefore increasingly interested in the implementation possibilities of these systems. However, current knowledge on these ITS implementation issues is poor with respect to e.g. technological requirements for ITS implementation, the contribution of ITS to general transport policy goals and the willingness of stakeholders to accept ITS. In general, public policymaking suffers from a lack of vision on integrated ITS implementation. This paper presents a view on an integrated ITS strategy for road traffic management. This view is based on a conceptual framework for the transport system in which transport processes are linked to stakeholders' behaviour. Within this view basic traffic management objectives are used to define consistent packages of ITS applications.
\end{abstract}

Keywords: ITS implementation, policymaking, traffic management.

\section{Introduction}

The importance of Intelligent Transport Systems (ITS) is growing rapidly. ITS refers to a large variety of innovative applications of information and telecommunication technology (ICT) to improve the performance of transport systems. The first reason for the increasing popularity of ITS is the huge development of the field of ICT, enabling R\&D on a variety of innovative applications. The second reason is the growing awareness of the negative externalities of transport systems, such as congestion, reduced safety, pollution, land use, and noise. Increasingly, pleas are made for breakthroughs in the development of transport systems to limit these negative externalities. The idea that ITS can significantly contribute to such breakthroughs has become very popular in the last decade. Instead of building additional infrastructures, transport policy is increasingly focusing on the issue of ITS strategies to avoid nonnecessary transport and to stimulate intelligent use of different travel modes and existing infrastructure capacity.

Although the expectations concerning the positive impacts of ITS are high and widespread, and the variety of ITS measures is steadily growing, there still is a considerable gap between what seems technologically possible and what has so far been able to be achieved in practice. In the past few years an increasing number of professionals have, therefore, stressed the need for exploring issues of ITS implementation (Underwood, 1990; Levine and Underwood, 1996; Van der Heijden and Wiethoff, 1999; Marchau, 2000). In this context, behav- 
ioural, societal, legal, institutional and political goals, impacts and conditions are addressed. The central notion in these publications is that policymakers do not have a clear picture of their goals and the ITS concepts contributing to these. Moreover, there is a general lack of knowledge about the infrastructure required, institutional and societal conditions for implementation, and the roles played by various stakeholders. This causes a conservative, riskavoiding attitude towards new developments among key stakeholders. At the side of ITS production industries, risk-avoiding behaviour is due to lack of robust long-term public transport policy strategies. This results in developing and marketing basic in-car applications (such as route information systems or advanced cruise controls). Public authorities tend to show a 'wait and see' attitude due to a lack of coherent vision. In addition, drivers are sceptical about costs and potential behavioural limitations due to ITS measures. In summary, ITS development and implementation is a very complex matter with a variety of aspects. A basic handicap for a targeted development seems to be the lack of vision on how ITS might be made attractive to key stakeholders.

The aim of this first paper in this special issue is to evaluate recent developments and present a visionary framework for an integrated ITS strategy for road traffic management. The paper scans recent developments and identifies promising developments in ITS with respect to road traffic management. By 'promising' we mean technologically feasible and societal preferred. Societal preferences are based partly on a recent state-of-the-art study performed by Marchau et al. (2000), which was commissioned by the Dutch Ministry of Transport and Public Works. Given the visionary approach, various assumptions will be made which, in the context of this paper, cannot be validated empirically. They are mainly based on professional discussions and knowledge, more widely reported in the ITS literature.

Since ITS refers to a very broad field of applications, we will start by classifying these applications in section 2 according to systems view on the transport system. In section 3 we will focus on ITS developments in the field of road traffic management. For these developments we address the question: what do we actually know about their state-of-development and their impacts on traffic performance. This exploration gives us ingredients for building a visionary framework for ITS in relation to road traffic management. In section 4, we present this vision based on a stepwise approach deduced from systems view in section 2 . This vision generates new challenges for research and policy development, which are briefly addressed in section 5 .

\section{Classifying ITS developments}

In the introduction it was mentioned that the applications of information- and communication technology cover a wide range of aspects of the transport system. To understand the various developments in ITS, it is important to structure them. The question is which rationale should be followed for structuring. The study by Marchau et al. (2000) adopts the conceptual scheme for the transport system presented in Figure 1. It focuses on the functional characteristics of different subsystems of the transport system. ITS developments are generally classified in literature in terms of their functional characteristics (see e.g. Chen en Pederson, 1997) which are functionally linked with the various subsystems in the transport system. Hence, the conceptual scheme in Figure 1 provides a useful basis for classifying and evaluating these ITS developments.

Figure 1 splits up the transport system into seven subsystems. Four subsystems comprise the transport system's physical features (infrastructure, vehicles, cargo \& passengers and spatial/economic patterns). The other three subsystems are the three markets: the traffic market, the transport service market and the transport needs market). These seven subsystems 
roughly tell us how major processes in the transport system function. Each subsystem generates its own unique processes and problems and has unique stakeholder interactions. From an analytical point of view, it is valid to regard them as subsystems. From a synthesis point of view (e.g. in policymaking), it is important to pay sufficient attention to the interactions between the subsystems. A lower subsystem facilitates (supports) the processes within the higher subsystems (in Figure 1 this support is indicated with an "S"). A higher subsystem, however, does not support processes in the lower subsystem: it places functional requirements on the facilities and services offered by the lower subsystem (in Figure 1 these requirements are indicated with an "R"). For example: there will be no traffic without roads (traffic requires roads), but once there are roads they support a large variety of traffic processes. Hence, in order to understand the conceptual scheme, the different natures of the interactions between the subsystems should be understood. We will first discuss each subsystem in more detail before relating the ITS developments to the scheme.

\section{Figure 1 about here}

We begin at the bottom of the figure and work our way up. The subsystem 'Physical transport infrastructure' refers to the variety of infrastructure networks and facilities for different travel modes (road, rail, shipping, pipelines, and air). These infrastructures are a necessary condition to facilitate traffic flows. Typical processes are the planning, design, realisation and maintenance of infrastructure.

Increasingly, there appears to be a shortage of road infrastructure capacity to handle total traffic demand. This shortage results in congestion. The degree of shortage is subject of intervention in the so-called 'Traffic market'. Typical of this subsystem is the tension between limited supply (infrastructure) and high demand (the number of vehicles to be accommodated). Operational traffic management aims at handling this tension in an acceptable way and can be considered a strategy for market intervention. Intervention between demand and supply has become a continuous activity within the transport system for almost all travel modes. The character and intensity of intervention can change due to e.g. the construction of more infrastructure capacity and/or the use of ITS applications to improve infrastructure capacity use.

'Vehicles' refers to the fleet of vehicles that is available to transport passengers or freight from one place to another. We distinguish different types of fleets (car, bus, train, ship, aircraft). Activities in this subsystem include vehicle R\&D, vehicle marketing and selling, fleet maintenance, and the like. The use of vehicles (lower in the transport system) asks for traffic rules and infrastructure capacity. The nature of this demand varies with the different functional characteristics of each transport fleet (e.g. maximum speed, professional drivers or not, use at dedicated lanes or in mixed traffic). Most of these fleets are subject to continuous technical improvement, among which the introduction of electronic devices to support driver tasks. Sometimes, new transport technologies are introduced, e.g. Maglev, high-speed trains or automated people-movers.

Choices regarding the use of subsets of the available vehicles to transport passengers or freight result from decision making by stakeholders operating in the subsystem called 'Transport service market'. Transport service development is in essence a matter of logistics: transport services include the organisation of trips for clients from an origin to a destination, using a specific mode (or perhaps a combination of modes), at a particular moment, according to a specific route through networks, for a certain price. In this market, logistics providers, transport companies and the passengers themselves seek a match between the demand for trips and the transport options (in fact, available transport capacity). This matching process is sensitive to aspects such as costs and time. Moreover, the access to information and the reli- 
ability of information concerning the alternative options increasingly appears to substantially influence logistic decisions.

The development of transport services is a reaction to an overt 'Freight and passenger transport demand'. This demand is measurable in terms of the number of passengers and the freight volume to be transported at a certain place and time. This demand basically results from the 'Spatial, economic and temporal dynamics' related to production and consumption activities in society, the highest subsystem of the conceptual scheme. At that subsystem decisions are taken on for instance the nature and spatial pattern of economic activities, the amount of free time for inhabitants and on policies for urban development. The resulting societal structure generates a certain hidden demand for transport. The hidden demand and overt demand are not equal. The explanation for this difference is basically found in economic theory. The degree to which this hidden demand results in overt transport behaviour, depends upon the operating of an intermediate market, here labelled the 'Transport needs market'. The transfer from hidden to overt transport needs, heavily depends upon the willingness to pay for physical transport. This is influenced by aspects such as the size of available time budget and financial budget for travelling, general transport price policies and the possibilities to substitute physical trips for virtual trips. In case the willingness to pay for physical transport is too low due to whatever reason, then a too low level of overt transport behaviour might be the result. This might frustrate the basic economic processes of production, distribution and consumption. In case the willingness to pay is relatively high (e.g. mobility costs are very low), this might cause an exponential growth of transport, which might also frustrate certain societal processes. Consequently, a good working transport needs market supports the processes at the highest subsystem, while in its turn these processes put requirements to the functioning of the transport needs market Further, the transport needs market puts requirements to the services offered by the lower subsystems. This brief explanation shows that intervention at the transport need market (e.g. high transport pricing, re-organising opening hours for shopping, introducing tele-education or tele-shopping) can significantly contribute to changing the level of actual demand for physical transport as compared to the level of hidden demand.

This conceptual view of the transport system is meant to explain the complex relationships among different parts of the system. Moreover, it enables us to improve our understanding of the differences in decisions taken in different subsystems and consequently to get a better perspective on the role played by the stakeholders involved. As will be argued and illustrated more extensively in sections 3 and 4, the nature of the transport system implies an interaction between these subsystems. This means that the market operations, which constitute the interfaces between the physical layers, are very important. It means that discussions on the interconnectivity of transport networks and the interoperability of transport services should be associated with the operations at the traffic market and the transport market respectively.

Using this conceptual scheme, we are now able to make the step towards a functional classification of the variety of ITS technologies by linking the design functionality of these technologies with the processes of the above-described subsystems. Table 1 shows such a classification. In this table, a link is made between the subsystems, the related public policy goals (deduced from Dutch national transport policy plans (V\&W, 1989, 2000), the ITS functional category and indicative ITS applications. No comprehensiveness is intended.

\section{Insert Table 1 about here}

In the 'transport need market', some ITS developments focus on applications to facilitate virtual mobility, aiming at a significant substitution for physical transport. Electronic services for distance working, commerce, learning or shopping, become increasingly popular. In 
the 'freight and passenger demand' subsystem, the focus is on ITS applications to improve pre-trip information (e.g. transport mode options, expected travel time, delays, costs) and articulate transport service preferences. Logistic planning in the 'transport service market' uses a variety of supportive electronic tools, for example for route planning and navigation, booking multi-modal transport services, tracking and tracing freight, or fleet management. ITS developments related to the subsystem 'vehicles' focus on the development of systems to improve the operational performance of vehicles, such as improved motor performance, vehicle control or driver support with regard to e.g. distance keeping, obstacle avoidance or lane keeping. The 'traffic market' is adopting a large variety of electronic systems for dynamic traffic management. ITS applications in this context focus on optimising infrastructure capacity use and assuring a safe and steady flow through networks. Examples are dynamic route information screens, lane assignment, real-time radio traffic information or ramp metering. Finally, in the 'infrastructure' subsystem, electronic systems are in the making and used for road status measurement for e.g. maintenance planning or for activation of dynamic traffic management.

Summarising, to explore the potentials and impacts of ITS it is important to differentiate according to the functional variety of applications. Diversification in scope and functional goals of ITS applications improves detailed knowledge about (potential) impacts of (new) applications. Moreover, it improves the feeling for possible attractive combinations of applications, as will be illustrated in section 4 .

\section{ITS for road traffic management: the state-of-the-art}

ITS for road traffic management is presently focused on three subsystems: the vehicles, the traffic market and the infrastructure. ITS developments related to these three subsystems, have been briefly indicated above, but will be further explored in this section. Moreover, since traffic directly results from logistic decisions, ITS for the transport market will be briefly addressed as well.

\section{a. Vehicles}

In-vehicle ITS applications are meant to improve motor performance, vehicle dynamics or to support driver tasks concerning e.g. speed control, distance keeping, navigation, roadway positioning and collision avoidance. Some systems are already in the early market introduction phase, like adaptive cruise control and collision warning. Most of these driver support systems are, however, in the prototyping phase and have been demonstrated in terms within experimental conditions. In recent years, for instance, fully automated car driving has been demonstrated in the US, Japan and Europe.

Various basic technical questions are related to these experiments (Marchau and Van der Heijden, 2000). A first issue concerns whether these systems can solely be based on invehicle technology or if they require support from communication with other vehicles and/or infrastructure systems. Automotive industries tend to develop applications as independent as possible from infrastructure facilities, since infrastructure adaptations usually take a long time. Another issue concerns the reliability of the technology: how sensible is the system performance to disturbances, e.g. bad sensoring due to temporary, degraded conditions (snow, fog), electromagnetic influences, insufficient data processing capacity, and the like. For instance, unexpected interference between in-vehicle electronic systems has been reported yielding complex liability issues (Van Wees, 1999). For the time being, uncertainty about this sensibility is an obstacle for introducing full-automated guided systems in less controlled traffic situations (such as mixed traffic). A third issue concerns the applicability of these systems. 
Should they be able to cope with the almost endless variety of road and traffic configurations or is it expected that a safe and reliable application is restricted to, for instance, the motorways? Certainly for the next decade, a limited applicability of these systems at secondary roads is expected: the sensing task is quite considerable and the decision rules to be implemented are too complex to handle in the early development stage. Perhaps an exception can be made for intelligent speed adaptation and adaptive cruise control systems, which have been proven to perform satisfactorily, even for some parts of the lower level road network.

Most of the technical developments are initiated by automotive industries. As described, serious difficulties have to be tackled, but nevertheless clear progress is being made and electronics are increasingly being implemented in new cars, buses and trucks. The inclusion of these electronics in new vehicles is used by automotive industries as a selling point to the market. More safety, more driver comfort and better performance are claimed. The question is how strong the basis of these claims is. The literature reports potentially significant positive impacts of crash recorder/black box, intelligent speed adaptation and tutoring systems (e.g. Gundy, 1994; Ward et al, 1996; De Visser et al, 1999). Adaptive cruise control could contribute significantly to less head/tail crashes, but (dependent upon the specific operating characteristics of the system) could also reduce road capacity use (e.g. Minderhoud, 1999). Moreover, both intelligent speed adaptation and adaptive cruise control might generate unexpected driver behaviour (less alertness, over-expectations, compensation for freedom limitations), which could eliminate positive safety impacts (e.g. Endsley \& Kiris, 1995; Hoedemaker, 1999). Finally, experts indicate that the impacts of these systems on environmental performance are hardly known (Marchau, 2000).

\section{b. Traffic market}

To support interventions in the traffic market, a variety of ITS applications have been introduced on a large scale. These applications focus on handling the tension between the demand for road infrastructure capacity and the actually available capacity, by guiding traffic flows in (parts of) the road network. Most of these applications are designed for handling the situation on the motorway network (see e.g. EU-programmes like Prometheus: EU, 1996)

Very well known is the system of Variable Message Signs (VMS), generally constructed above the roads to warn drivers of upcoming congestion and, if possible, to suggest an alternative route. Developments in this field focus on applications for major transport corridors (Morello et al, 1999), and on the type and way information has to be presented to the drivers (Rama \& Luoma, 1999). Positive impacts of VMS in terms of reductions in the length of traffic jams up to about 30\% have been reported (e.g. Kraan, 1999). Another way of influencing route choice is using Radio Data System-Traffic Message Channel (RDS-TMC). The system provides the driver with traffic information on the radio. RDM-TMC is becoming increasingly popular in Europe and seems to have a positive impact on traffic performance. Japan has, since the mid 1990s, been working on linking this type of information system to invehicle navigation systems. Levinson et al. (1999) indicate that better route information can induce an average lower travel time and less uncomfortable trips. However, these authors warn that this may cause an increase in the number of trips. Another impact reported in literature is that changes in the use of different road networks (in particular more use of lower road networks) might negatively influence traffic safety.

The need for improving the efficiency in road capacity use has led to several applications: ramp metering, dynamic lane use regulations and variable speed limits are common nowadays on Dutch motorways. These systems are generally based on the permanent measurement of traffic flow intensity in relation to speed control. However, access strategies for ramp metering are generally not systematically related to traffic flows on secondary roads. These road capacity optimisation systems are sometimes linked to dedicated use of lanes for 
special target groups such as freight trucks. Video-based trajectory speed control systems are implemented to control compliance to speed limits. V\&W (1998) predicts a 20\% lower level of serious accidents due to the introduction of this system. The application of ITS for managing traffic at lower road networks lags behind developments at motorways. Nevertheless, some developments are, in this respect, of interest. One development is the optimisation of traffic light systems at road crossings based on traffic intensity measurements (e.g. Shin, 1999), yielding less 'stop \& go' traffic movements. Another is the application of parking guidance systems in urban areas, sometimes linked to park \& ride services. A potential reduction in traffic flows in urban areas of 5-10\% has been reported (Kempter et al, 1995; Nakamura et al. 1999).

There is significant evidence that the introduction of ITS to support traffic management has caused a significant (local) increase in road capacity and traffic safety. Recent developments also try to influence the local demand for road capacity at specific parts of the network by introducing local electronic payment systems. The aim is to reduce demand in peak hours by strengthening the principle of paying for scarcity. The implementation of this principle is not without the possibility of failure, due to a lack of in-depth knowledge about behavioural impacts, technological and legal complexity (e.g. fraud-insensible vehicle registration), inducing uncertainty about the contribution to public goals. Among others, May \& Milne (2000) report a reduction in road traffic during pay times of 10 to $15 \%$. However, most (positive) expectations of impacts of road pricing are based on model simulations, assuming a level of price-elasticity not always supported by empirical measurements.

\section{c. Infrastructure}

Traffic managers base their operational traffic control on available road capacity. ITS can be used to optimise available physical capacity. One field of application deals with automated status measurement (inspection) to optimise road maintenance programmes and improve road availability. Another field of application focuses on capacity management during special conditions (roadwork, snowfall, heavy rainfall). These conditions require parts of the network to be closed for normal road users during short periods. In these situations speed adaptation, warning information, and alternative route information to road users is important. Here, the above described ITS applications for the traffic market can be used in case they are available. If not, mobile systems can be installed at strategic points, operating stand-alone in terms of energy supply and wireless communication (Saccon \& Bebenek, 1999).

A final issue getting increasing attention, is the use of dynamic changes in the number of lanes for a temporary capacity increase. Simulation studies indicate a potential $30 \%$ increase in throughput of vehicles due to an extra lane (Tampère, 1999). With regard to this option, the technology for temporarily widening/ narrowing lanes is just as crucial as the corresponding traffic control technology. In these situations lane marks are not fixed (paint), but based on e.g. variable visual signals in the road-surface. Of course, narrowing lanes in order to create an extra lane requires a substantial reduction in the average speed to avoid higher risk of collisions. Hence, a structural link with traffic management strategies is essential. As far as the authors know, the technological elaboration of this innovative infrastructure capacity concept is still in an experimental stage.

\section{d. Transport market}

Although in the context of traditional traffic management, logistic management is not a real issue, the conceptual scheme in Figure 1 shows us that transport service decisions precede traffic patterns. Hence the scheme suggests taking into account developments at the level of the transport market in order to enrich the awareness of mutual relationships among the subsystems. Decisions taken in the transport market have serious impacts on the traffic volume 
on certain routes at certain times of the day. As such we assume and experience an increasing importance of linking operational traffic management with logistic service development. Developments in this field can be characterised in terms of 'making logistic decision making and management smarter'. Many ITS applications are developed and successfully applied to improve commercial vehicle operations by e.g. route planning, tracking and tracing of cargo, and by decoupling physical and administrative flows (e.g. EU, 1996; Wilfong, 1996; Bellela et al, 1998). Significant impacts on efficiency improvements in transport capacity use and service quality improvements have been reported.

From these brief explorations of ITS developments, the conclusion can be drawn that different ITS applications result in making the road 'smarter', making the vehicle 'smarter', better supporting the driver and bringing logistic performance at a higher level. Making the road smarter implies a further optimisation of the traffic flow between nodes in the network. The main player in this respect is the road traffic manager. Strategies to make the vehicle smarter mainly focus on the local interaction of the vehicle with other vehicles, without taking the performance of the traffic flow into account. The key player here is the automotive industry, possibly in interaction with insurance companies. The improvement of driver's support is focused on the individual travel and driving behaviour. This development is driven by efforts from the automotive industry as well as from travel information providers. Finally, logistic service development aims at better trip chain quality and at improving the time-space spread of demand according to the available road and fleet capacity. Key players in this field are fleet owners and providers of multi-modal transport services for freight and passenger transport.

Evaluating these trends, the main observation is that they tend to develop separately from each other. For example:

- route decisions by logistic planners lack access to reliable real-time and short-term predictive traffic information;

- the parameters for ramp metering are set on the basis of local traffic intensity at the motorway and not by taking into account the situation on adjacent parts of the entered network;

- distance keeping between vehicles is based on a parameter setting of in-vehicle technology that does not fit in with the capacity goals of the road traffic manager;

- driver-oriented information is mostly limited to road traffic and does not include real-time information on public transport options. Consequently, the option of the use of multimodal travel chains remains almost hidden for the driver.

The ultimate consequence of these separated trends in ITS R\&D and its applications is suboptimisation from the perspective of total traffic management. Opportunities for influencing strategic and operational decisions on trip planning (time of departure, route, mode) are not fully used. In its turn, this lack of mutual functional interaction between ITS applications generates extra uncertainty about the possible impacts of new ITS introductions on other subsystems. ITS developments are not systematically linked with the chain of decision making on travel and driving behaviour throughout the various subsystems of the transport system. Assumptions in R\&D and applications are made based on the nature of decision in other subsystems of the transport system that might insufficiently fit with reality (see e.g. Nijkamp et al, 1996). In the end, this might cause disappointing impacts of ITS and a delay regarding the implementation of more advanced ITS applications. This explains the somewhat sceptical attitude of experts in the field of ITS on ITS potential and future development process as described by Marchau and Van der Heijden (1998, 2000).

\section{ITS-based road traffic management in future}


In the previous section, it was argued that various promising ITS applications are in the making or subject to implementation programs. A major problem was formulated: these developments are insufficiently mutually co-ordinated, causing a strong tendency to sub-optimisation of the entire transport system. From a traffic management point of view, a stronger focus on linking different applications in coherent technology packages is required. In answer to this need, this section presents a view on road traffic management in the future. This view consists of an approach based on a sequence of six steps, being aimed at influencing the decisionmaking process of travellers and drivers. These steps are deduced from the description of the transport system presented in section 2, starting with travel behaviour (the transport market) and ending with car driver behaviour (the traffic market). We start our view from the moment a positive decision has been taken to make some trip from $\mathrm{O}$ to $\mathrm{D}$. Hence, we skip the step of influencing the need for travelling (the transport need market). Each step is based on a specific objective considered from the position of the road traffic manager. These objectives are: at the Transport market:

a. larger temporal-spatial dispersion of travelling,

b. improved multi-modal travelling,

at the Traffic market:

c. co-ordinated use of different road networks,

d. using road capacity with priorities,

e. control of driver behaviour,

f. effective response to incidents.

These objectives will be elaborated and discussed below.

\section{a. Larger temporal-spatial dispersion of travelling}

One of the major problems with traffic management is that the occupation of road networks fluctuates in time and space. Generally, there exists no steady state during a long period. Traffic management copes with traffic waves and peak loads on the networks and has, until recently, merely been focused on guiding road users after the moment of their entering the road network. Dynamic traffic management could, however, start earlier in the process by influencing pre-trip decision making. In particular the road traffic manager would (in case of peak loads) be interested in influencing the decisions of an individual traveller on:

- Postponing the trip to another (off-peak) moment and/or

- choosing another destination than initially preferred, being more accessible and offering the same activities and/or

- shifting mode in favour of an alternative travel mode and/or

- changing the route plan in favour of less intensively used routes.

All these interests are related to a better allocation of demand to available road capacity. Spreading in time and space is assumed to contribute significantly to lower demand peaks on certain links in the networks at certain moments and, as such, contributes to less congestion in these parts of the network. To arrive at a situation of significant influence on pre-trip decision making, ITS increasingly offers opportunities.

A basic requirement is the general provision of real-time traffic information as well as short-term traffic flow forecasts. Of course, this requires permanent measurement of traffic intensity and parallel running of traffic forecast models. Since traffic is more and more a crucial factor in socio-economic processes and the road traffic network becomes more and more unreliable due to structural and incidental congestion, a more mature performance measurement system should be implemented in areas with, on average, intense traffic. In large urban areas these measurements are made nowadays, using advanced electronics in the motorway infrastructure. Next, these data are processed in traffic information centres and, if necessary, traffic 
information is given to motorway users on e.g. proper speeds and alternative (motorway) routes. However, a problem is that, in general, these electronic systems are not applied yet at secondary road networks feeding the motorway network. The predictability of traffic flows is negatively influenced by this selective measurement. From the perspective of available information- and telecommunication technology, this is increasingly unnecessary. In the future predictability might be improved by unique vehicle identification, the registered scheduling of a trip (destination and time) by the traveller and by road-capacity slot reservation (see further).

A second requirement is that freight transport companies and travellers have quick and easy access to actual and expected network traffic information. Assuming that traffic information centres are able to provide this information in the future in a more accurate and reliable way, two developments are relevant for receiving and using the information. A basic possibility is to use (mobile) telephones linked to speaking devices, using standardised communication protocols by the traveller to collect selective information. An alternative approach is based on the growing number of households having access to the Internet, which offers the possibility for collecting tailor-made and visualised information. A further step offers the concept of 'personal intelligent travel assistant' (PITA). This could be an on-board computer in vehicles or mobile communication facilities for travellers with wireless access to computers at the traffic information centres. The intelligence within a PITA environment involves the specification of individual preferences based on past behaviour, given certain traffic conditions. This specification is translated into knowledge rules to advise the driver or traveller in actual or expected travel situations. Next to pre-trip travel support, the concept of PITA will be able to play a significant role for on-trip travel support as well (see next objective).

\section{b. Improved multi-modal travelling}

From the perspective of dynamic traffic management, an optimal use of available transport facilities should be pursued. This optimisation should not be limited to roads and car use, because this might lead to sub-optimisation in case capacity is available in adjacent public transport (train, subway, bus). Therefore, more systematic links should be made between the road system and public transport, in particular in urban agglomerations where the probability of congestion is generally high. The Park \& Ride (P\&R) concept is meant to fulfil this need and has been implemented in several urban areas in the past decade. However, the concept has had limited success, in spite of growing congestion problems in and around these urban areas. One explanation is that information supply to car drivers about P\&R services is too limited and too static. Advanced information- and communication technology should, in the future, improve this situation significantly.

Present information supply starts in the pre-trip stage of trip planning with (in general) separated information systems about road traffic and public transport services where little attention is paid to the transfer points. A greater problem concerns the static on-trip information about P\&R supplied to the car drivers. Generally, this consists of routing information to transfer points starting at motorways. Based on this limited information, car drivers are not able to make a clear trade-off between continuing in using the car towards the destination or switching at the transfer point to public transport services. Making such a trade-off decision requires additional information on the costs of continuing to use the car, related to for instance electronic toll to be paid, expected travel time given congestion, expected probability of parking lot availability and costs of parking. These car-related costs should be compared to information on travel time to the transfer point, the availability and costs of parking at the transfer point, the waiting time for the next transfer service and the remaining travel time and costs to the destination. 
Hence, reducing travel uncertainty for the car driver requires the supply of substantial amounts of information as well as a quick support of individual evaluation of this information. Basically, available ITS technology enables the collection and supply of these data. Part of the information required is related to the geographical position of the car driver, which can be, for instance, determined by GPS. For public transport and large fleet owners in freight transport, the use of these systems is becoming common practice. This position-related information should be extended with real-time (and preferably short-term forecasts on) road traffic, parking information and information on public transport services. This information is available and sometimes presented to car drivers using electronic information screens along motorways. The local/regional traffic information centre could transmit this information to the vehicle board computer or to the above-mentioned PITA, to match with the more static position information. The evaluation of the two options (continue to use the car, or switch to transfer point) can be supported by implementing the driver's personal decision rules, based on prespecified preferences and knowledge rules deduced from revealed behaviour.

In the future, multi-modal travelling could further be enhanced by adding options, for instance, for reservation of parking space at the transfer point, or a bicycle, a seat in a shared taxi or train. Moreover, ideas have been formulated for offering additional services at transfer points, such as laundry or grocery shopping. A list of grocery articles can be ordered by electronic mail, collected by the shopping service, and picked up as soon as the transfer point is left again at the return trip. Evidently, these services require an interactive transmission of information between the traveller and the service information centre.

\section{c. Co-ordinated use of different road networks}

Both previously discussed objectives focus on limiting peak loads in the road network by shifting car drivers to other periods or other transport modes. Basically, the application of these two objectives should relax the problems of operational traffic management within the context of the tension between local demand and supply of road capacity.

Once the volume of car drivers is given, the third objective focuses on a more coordinated use of primary and secondary road networks in a region. Presently, traffic management is almost limited to urban and rural motorways. In situations of congestion at motorways in the surroundings of urban agglomerations, practice shows a substantial and hardly controlled use of the secondary road networks. This often generates very serious traffic problems in parts of the urban area as well. This problem becomes more severe because in many situations different authorities are responsible for the traffic management at different road networks and, consequently, good co-ordination is often absent. Generally, supra-regional traffic managers are responsible for handling the traffic at the motorways and local traffic managers for handling the traffic at the secondary road networks. Moreover, they often use mutually non-compatible information- and communication systems, which is the result of the use of different technology standards in the past.

Perceiving and managing all road networks as an integrated system offers better opportunities to inform drivers, to temporarily create alternative routes and to influence traffic light installations for buffering traffic at several places in the network. This points to the need for gradually introducing dynamic traffic management technology to the secondary network in order to enable better co-ordination of traffic management within a region. In that case the traffic manager requires a systematic collection of information about the traffic situation in different parts of the network as well as instruments to influence traffic flows at different networks simultaneously.

\section{d. Using road capacity with priorities.}


Focusing on the motorway network, a next objective of traffic management relates to the strategy for assigning road capacity to road users. The current base rule is that all users can ask for capacity at every place in the network at any time, except for some dedicated lanes for freight trucks, buses or carpooling. Moreover, in a growing number of situations local access depends upon payment. Apart from these exceptions, for non-dedicated parts of the road network, payment might not be a sufficient instrument to match demand with scarce road capacity: congestion is still reality, although less than before.

An option for the future is to combine payment with a more active assignment strategy of road capacity, enabled by advanced information- and telecommunication technology. Given the future use of on-board computers or PITA in the car, a strategy based on slotreservations could be considered. A capacity assignment strategy based on slot-allocation within the margins of available capacity is basically accepted for air traffic and rail traffic. In discussions on introducing pay lanes, this is also a serious point. Slot management is important for travel quality assurance (mainly guaranteeing an average travel time). Application of such a slot management strategy on the road network implies not only a system of slotreservation, for instance by calling the computer at the on-ramp of the motorway chosen by the driver. A prerequisite is the general introduction of electronic vehicle identification. The unique code for each vehicle is matched at the on-ramp with the reservations to avoid or allow for entering the motorway and to assure electronic payment (including payment for noshows).

The advantage of such an active capacity assignment approach is that control of the flow on the motorway can be improved. Regulation of reservations can be made by price differentiation: (certain) reservations for a long period in advance (e.g. by commuters) for certain access times with high prices versus (uncertain) last-minute reservations with low prices. An auction system might even be considered in this context. Another advantage is that in case of threatening traffic jams, no reservations can be made and no access is allowed. Since this information is given to the driver in time (e.g. 10 to 15 minutes before the preferred entering), the driver might choose an alternative route or travel mode with a minimum loss of time. Overall, a better trip quality can be guaranteed to motorway users in terms of (average) speed and steady flow. On the other hand, incidents might still occur, generating traffic jams. In those cases where the promised quality cannot be delivered, repayment should be considered.

Of course, this way of thinking about capacity assignment is rather revolutionary.

From ITS technology point of view, there seem to be little obstacles. The main obstacles deal with legislative, property and societal equity issues. Presently, roads mainly belong to the public domain and therefore nobody can be excluded from using them once a general road tax has been paid. Access to the system is based on the sequence of showing up at the entrance of the system, for instance at the on-ramp of motorways. Long-term reservations in advance might significantly violate this principle. On the other hand, the present open use generates so many disadvantages that a serious discussion on this rule seems legitimate. This discussion might be linked to the idea of allocating certain amounts of travel rights (e.g. a certain amount of vehicle kilometres per year) to different categories of travellers, including the option of selling and buying at an auction. It might be worthwhile to experiment with this approach at parts of the road network being developed by private investors and/or parts of the road system dedicated for special target groups, such as business drivers and road freight transport. Such an experiment should give us more insight into the societal costs and benefits of the concept as compared to the present system.

\section{e. Control of driver behaviour}


Once car drivers are participating in traffic, compliance of these drivers to norm behaviour assumed in general traffic rules is a major interest of traffic management: do not exceed speed limits, do not behave aggressively, do not change lanes unnecessarily, keep sufficient distance to the preceding car, and so on. Driving behaviour studies, however, indicate that deviant behaviour in traffic is the rule rather than the exception (as e.g. information on speed limit violation indicates; see e.g. Van der Heijden \& Molin, 1999). The assumption is that reduction of deviant behaviour significantly contributes to a better traffic flow performance. Traditionally, education, engineering (infrastructure design) and enforcement by police have been the main instruments to reach this goal. Nowadays ITS is increasingly considered to be a promising instrument too.

Previously discussed objectives have addressed ITS applications for the support of travel behaviour. These systems are mainly based on the idea of better informing drivers about their opportunities to travel from origin to destination. Within the category of driving support systems, applications to inform drivers with regard to e.g. vehicle status, speed, alternative routes or blind spot obstacles, are gradually becoming standard selling points for new vehicles. These developments have been described in the previous section. From the perspective of traffic management, a more controlling influence on driver behaviour is desired in certain situations. For instance the combination of enforced speed limitation and lane keeping can contribute to a better use of scarce road capacity. This becomes especially relevant in case of dynamic adjustment of lane width in situations of high traffic density, in order to temporarily generate an extra lane. In addition, in cases of roadwork, slipperiness or heavy rainfall, speed enforcement is relevant. Hence, electronic support of the driver tasks and traffic management decisions should interact more intensively. In terms of ITS applications, coordination between infrastructure-related information and autonomous handling of in-vehicle systems is required for such a concept. The combination of in-vehicle technology for adaptive cruise control and speed adaptation with roadway technology for flow intensity measurement and optimal speed determination, provides an attractive base for such a co-ordination.

The ultimate consequence of this approach is the application of fully automated driving. As argued before, it is assumed that full application of this vehicle control concept will only be possible in the long run, at least for mixed traffic situations. Large-scale application at dedicated roads for special traffic (buses, trucks, people movers) is expected within a period of ten years, given the present experiments in different places in the world.

\section{f. Effective response to incidents}

The final objective of ITS-based traffic management focuses on quickly eliminating traffic disturbances based on incidents or accidents. In the present situation, small incidents too often cause long-lasting traffic jams within the road network. Clearing the road almost immediately after an incident has occurred, is generally not possible because of guilt and liability issues. The traffic police have to investigate the situation before clearance.

In a context of ITS, avenues for a much quicker response to such situations are opened. It starts with improving emergency calls and initiating a quick emergency reaction. This might, for instance, be linked to the electronic monitoring of the driver status. In case of illness (e.g. heart attack), drugs or alcohol use, causing dangerous driving behaviour, this system warns the driver. It is even technically feasible to let the system take over the driving tasks and park the vehicle along the road, in order to avoid accidents and/or secondary incidents. This could easily be extended with incident warning at the traffic management centre: camera observations or automatic signalling from a roadway sensor or from the in-vehicle electronic system.

In case of incidents or accidents on the road, the treatment of issues of guilt and liability should no longer (only) require extended police investigation on the spot. ITS offers sev- 
eral other possibilities: instantaneous alarming to traffic manager and first aid, data from a black box in the vehicle makes it possible to reconstruct the last minutes of the vehicle behaviour before the crash, digital photography and camera registration along the infrastructure enables computer-animated reconstruction afterwards. Evidently, insurance companies should be stronger involved in these developments, to explicate their specific, long-term preferences, to adjust their rules and operations, and to work more closely together with traffic managers to reduce societal costs due to long traffic jams.

\section{Final remarks}

This article presented a conceptual framework of the transport system and its subsystems in order to understand developments in the field of Intelligent Transport Systems (ITS). These developments were classified according to this framework. It's concluded that the introduction of intelligence in the transport system, which in fact focuses on the application of advanced information and telecommunication, refers to a large variety of applications with occasionally very different goals. We saw that these applications have a high potential for improving traffic management. However, it is essential that the development and implementation of these applications are co-ordinated to realise this potential.

To investigate whether such co-ordination is happening, the main lines of recent ITS developments for were evaluated in terms of reported knowledge on the stage of technology development, expected impacts, and perceived implementation problems. From this exploration we concluded that there is a strong tendency to develop new applications from the perspective of a single goal. Different stakeholders take initiatives to develop ITS applications for isolated problems: traffic managers focus on traffic flow management instruments, automotive industries focus on in-vehicle support of drivers, telecommunication industries focus on applications for the support of freight logistics. Co-ordination of these efforts is the exception rather than the rule. Moreover, most of these developments are too much the result of a technology push instead of being deduced from a public policy view on transport system performance.

Therefore, a third part of this article focused on presenting an integrated view on the role of ITS in future traffic management. Real transport system performance improvements can be gained by thinking about ITS not starting with the question "what is technologically possible?", but with the question "which objectives should these technologies serve?" What services are possible and required within given limitations of space, environment and investments? The answer to this question should lead us to preferences with regard to the use of ITS applications. The view on traffic management presented in this article emphasised the need for a functional linking of logistic decision making with multi-modal traffic management and driver behaviour. Inevitably, this implies a functional co-ordination of ITS applications. Examples were described for each of the six objectives being introduced.

The six objectives should lead us to consistent packages of ITS applications. They should be applied simultaneously to contribute to the pursued reduction of traffic problems in certain areas. In this view a real priority for achieving the six objectives is difficult to make: they constitute an integrated multi-dimensional framework. It makes little sense to exclusively focus on measures based on just one objective. Reducing motorway use is only possible when other road networks can handle higher traffic densities in a proper way and/or when alternative travel services are available. Furthermore, demanding higher prices from drivers for road use is only acceptable when these drivers are provided with other options as well: change the time schedule, switch to public transport, choose another route, increase car occupancy, and so on. In short: public traffic management policies should be based on a transport system ap- 
proach and on understanding dynamic choice behaviour of the stakeholders within in this system. It implies the need for starting traffic management strategies at the transport service market, thus including the supply of information for integrated trip planning.

It is obvious that we still have a long way to go before these objectives will be realised. However, many ingredients are already present. They require a good framework for technical integration and co-ordinated implementation. More research on the robustness, applicability and impacts of the technology is required. Furthermore, a stronger co-ordination between major stakeholders in this field is essential to reach a more elaborated and guiding view on future developments (what is wanted, what is possible). Moreover, possible institutional blockades for implementation should be gradually eliminated, such as rules for liability or the diversion of responsibility between national, regional and local authorities for different parts of the road system. A discussion about the present unlimited individual travel rights should be part of that institutional discussion. Finally, it is important to feed these discussions with more in-depth knowledge about the costs of development and the benefits of implementation.

\section{References}

Bellela, P., D. Millar and S. Sharma (1998), ITS field operational test cross-cutting studycommercial vehicle operations - roadside, Report no. FHWA-RD-99-036, US Department of Transportation, Washington DC

Chen, K. and J.E. Pedersen (1997): ITS functions and technical concepts, in: Proceedings of the 4th World Congress on Intelligent Transport Systems, ITS Congress Association, Brussels

De Visser, W., V. Marchau and R. van der Heijden (1999): The cost-effectiveness of future driver support systems, D. Roller (eds.): Advances in automotive and transportation technology and practices for the $21^{\text {st }}$ century, Proceedings of the ISATA-conference 1999, Croydon, UK, pp. 421-428

Endsley, M. and O. Kiris (1995), The out-of-the-loop performance problem and the level of control in automation, Human Factors, vol. 37, pp. 381-394

EU (1996), Progress in telematics applications for road transport in Europe, European Union Commission - DG13, Brussels

Gundy, C. (1994), Safety implications of electronic driving support systems, Report R92-85, Stichting Wetenschappelijk Onderzoek Verkeersveiligheid (SWOV), Leidschendam, the Netherlands

Hoedemaker, M. (1999), Driving with intelligent vehicles: driving behaviour with adaptive cruise control and the acceptance by individual drivers, Dissertation University of Technology Delft, Delft University Press, the Netherlands

Kempter, S., P. Allee, D. Hardt, E. Wittmann and W. Grossmann (1995), Dynamic P\&R information within Munich Comfort: system design and evaluation, in: Proceedings of the Second World Congress on Intelligent Transport Systems, VERTIS, Tokyo, pp. 2367-2372

Kraan, M. (1999), Evaluating network wide effects of variable message signs in the Netherlands, Transportation Research Record no. 1689, pp. 60-67 
Levine, J. and S. Underwood (1996): A multiattribute analysis of goals for intelligent transport system planning, Transportation Research C, vol. 4, pp. 97-111

Levinson, D., D. Gillen and E. Chang (1999), Assessing the benefits and costs of intelligent transportation systems: the value of advanced traveller information systems, PATH Working Paper UCB-ITS-PRR-99-20, Institute of Transportation Studies, University of California, Berkeley

Marchau, V. (2000): Technology assessment of automated vehicle guidance: prospects for automated driving implementation, Dissertation, University of Technology, Delft, Delft University Press, the Netherlands

Marchau, V. and R. Van der Heijden (1998), Policy aspects of driver support systems implementation: results of an international Delphi study, Transport Policy, vol. 5, pp. 249-258

Marchau, V. and R. Van der Heijden (2000), Introducing advanced electronic driver support systems: an exploration of market and technological uncertainties, Transport Reviews, vol. 20, pp. 421-433

Marchau, V., R. van der Heijden and W. Vree (2000), Strategische ontwikkelingen rond verkeersbeheersing: de rol van ITS, Report Faculty of Technology, Policy and Management, Delft University of Technology, The Netherlands (in Dutch)

May, A. and D. Milne (2000): Effects of alternative road pricing systems on network performance, Transportation Research A, vol. 34, pp. 407-436

Minderhoud, M. (1999), Supported driving: impacts on motorway traffic flow, Dissertation University of Technology Delft, Delft University Press, the Netherlands

Morello, S., A. Winder, M. Schintu and B. Leger (1999), European approach to improving cross-border traffic management: results of the Franco-Italian trans-alpine surveys in the Hannibal project, in: Proceedings of the 6th World Congress on Intelligent Transport Systems - ITS: Smarter, Smoother, Safer, Sooner, ITS America, Washington DC

Nakamura, H., K. Kato and T. Utsumi (1999), An applicability study on the dynamic P\&R system by a traffic simulation model incorporating a user behaviour model, in: Proceedings of the 6th World Congress on Intelligent Transport Systems - ITS: Smarter, Smoother, Safer, Sooner, ITS America, Washington DC

Nijkamp, P., G. Pepping and D. Banister (1996): Telematics and Transport Behaviour, Springer, Berlin

Rama, P. and J. Luoma (1999): Comprehension of VMS in Europe, in: Proceedings of the 6th World Congress on Intelligent Transport Systems - ITS: Smarter, Smoother, Safer, Sooner, ITS America, Washington DC

Saccon, F. and F. Bebenek (1999), Innovations in work zone traffic management, in: Proceedings of the 6th World Congress on Intelligent Transport Systems - ITS: Smarter, Smoother, Safer, Sooner, ITS America, Washington DC 
Shin, E. (1999), Arterial signal optimisation reflecting types of arriving vehicles at intersections, in: Proceedings of the 6th World Congress on Intelligent Transport Systems - ITS:

Smarter, Smoother, Safer, Sooner, ITS America, Washington DC

Tampère C.M.J. (1999) Dynamisch Dwarsprofiel: een verkenning van de verkeersafwikkeling op smalle stroken. TNO-rapport Inro/VK1999, Delft. (In Dutch)

Underwood, S. (1990), Social and institutional considerations in intelligent vehicle highway systems, in: Automated Highway/Intelligent Vehicle Systems: Technology and Socio-

Economic Aspects, Society of Automotive Engineers, Warrendale, pp. 59-76

Van der Heijden, R. and E. Molin (1999): The societal support for electronic driver support systems: the case of the intelligent speed adapter; in: R. Van der Heijden and M. Wiethoff (eds.): Automation of Car Driving; Exploring Societal Impacts and Conditions, TRAIL Studies in Transportation Science, Delft University Press, Delft, The Netherlands, pp. 193 - 208

Van der Heijden R. and M. Wiethoff (eds.) (1999): Automation of Car Driving; Exploring Societal Impacts and Conditions, TRAIL Studies in Transportation Science, Delft University Press, Delft, The Netherlands

Van Wees, K. (1999): Advanced vehicle control systems - legislation and safety issues, ISATA Magazine, vol. 7, pp. 30-32

V\&W (1989), National Transport Structure Plan II, Ministry of Transportation and Public Works, The Hague, The Netherlands (in Dutch)

V\&W (1998), Report on Telematics for Transport and Traffic III - Better Utilisation, Less Congestion, Ministry of Transportation and Public Works, The Hague, The Netherlands (in Dutch)

V\&W (2000), National Transport Structure Plan III, Ministry of Transportation and Public Works, The Hague, The Netherlands (in Dutch)

Ward, N, M. Humphreys and S. Fairclough (1996), A field study of behavioural adaptation with and Autonomous Intelligent Cruise Control System, in: Proceedings of the International Conference on Traffic and Transport Psychology, Valencia, pp. 15-19

Wilfong, R. (1996), Navigation and mobile telecommunication technologies for European road freight operations in the late 1990s, Dissertation, University of Technology Delft, Delft University Press, the Netherlands 
Table 1: $\quad$ Indicative relationship between transportation subsystems, policy goals and the variety of ITS applications

\begin{tabular}{|c|c|c|c|}
\hline Subsystem & policy goals & ITS functionality & possible ITS application \\
\hline organisation of society & $\begin{array}{l}\text { optimise mobility of peo- } \\
\text { ple, goods and information }\end{array}$ & & \\
\hline transport need market & $\begin{array}{l}\text { reduce unnecessary physi- } \\
\text { cal transport }\end{array}$ & $\begin{array}{l}\text { systems for facilitating vir- } \\
\text { tual mobility }\end{array}$ & $\begin{array}{l}\text { electronic commerce; } \\
\text { tele-working; } \\
\text { tele-education }\end{array}$ \\
\hline freight and passengers & $\begin{array}{l}\text { optimise access to and use } \\
\text { of transport system }\end{array}$ & $\begin{array}{l}\text { information supply on } \\
\text { transport services; } \\
\text { booking of services }\end{array}$ & $\begin{array}{l}\text { park and ride information; } \\
\text { public transport services in- } \\
\text { formation; } \\
\text { traffic information on ra- } \\
\text { dio, teletext; } \\
\text { internet booking services }\end{array}$ \\
\hline transport service market & $\begin{array}{l}\text { improve logistical planning } \\
\text { (modal split, route choice, } \\
\text { time) in favour of safer, } \\
\text { cheaper and environment- } \\
\text { friendly transport }\end{array}$ & $\begin{array}{l}\text { pre-trip planning support } \\
\text { systems } \\
\text { systems for logistic optimi- } \\
\text { sation }\end{array}$ & $\begin{array}{l}\text { (multi-modal) trip reser- } \\
\text { vation } \\
\text { route planning systems } \\
\text { telecommunication for fleet } \\
\text { management and opera- } \\
\text { tional control (tracking, tra- } \\
\text { cing); } \\
\text { trip matching systems (e.g. } \\
\text { carpooling) }\end{array}$ \\
\hline vehicles & $\begin{array}{l}\text { improve driver's comfort, } \\
\text { behaviour and vehicle con- } \\
\text { trol }\end{array}$ & $\begin{array}{l}\text { smart motor technology } \\
\text { driver support systems }\end{array}$ & $\begin{array}{l}\text { self-diagnostic engine con- } \\
\text { trol systems } \\
\text { crash recorders; } \\
\text { reverse parking aid; } \\
\text { tutoring systems; } \\
\text { navigation systems; } \\
\text { adaptive cruise/speed con- } \\
\text { trol; } \\
\text { lateral/longitudinal control; } \\
\text { co-operative driving; }\end{array}$ \\
\hline $\begin{array}{l}\text { physical transport infra- } \\
\text { structure }\end{array}$ & $\begin{array}{l}\text { maximise capacity with } \\
\text { limited physical extension } \\
\text { maintain quality }\end{array}$ & $\begin{array}{l}\text { lane optimisation technol- } \\
\text { ogy } \\
\text { infrastructure status control } \\
\text { systems }\end{array}$ & $\begin{array}{l}\text { dynamic lane configuration } \\
\text { adaptation } \\
\text { surface measurement and } \\
\text { deterioration detection }\end{array}$ \\
\hline
\end{tabular}




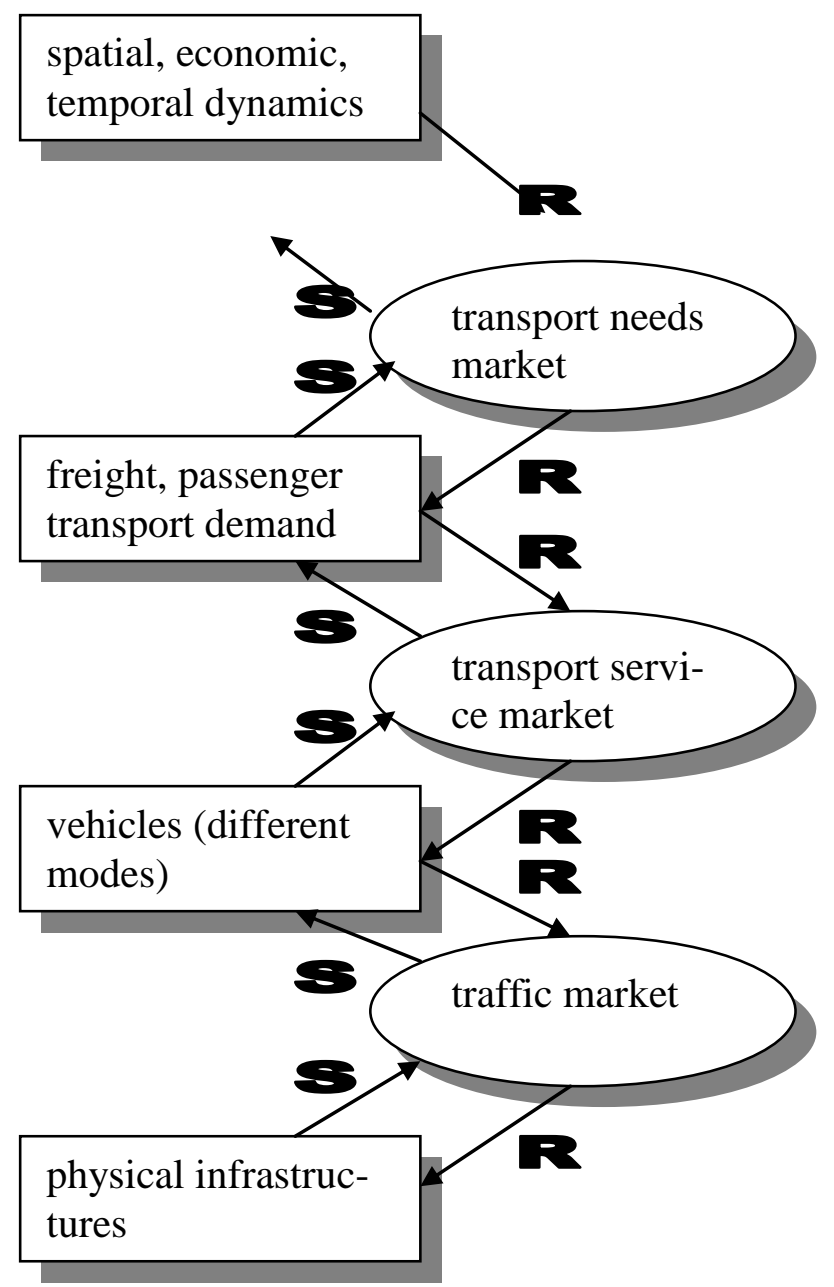

$\mathrm{S}=$ support of processes at higher subsystems

$\mathrm{R}=$ requirements to subsystem's processes/facilities 